\title{
Information Ethics as a Factor in the Development of Digital Economy
}

\author{
Shmyreva O.I.* \\ Department of philosophy and history \\ Voronezh State University of Engineering Technologies \\ Voronezh, Russia \\ e-mail: oishmyreva@rambler.ru
}

\author{
Chernigovskikh I.V. \\ Department of philosophy and history \\ Voronezh State University of Engineering Technologies \\ Voronezh, Russia \\ e-mail: igrchernigovskix@ @ambler.ru
}

\author{
Ponomareva E.Y. \\ Department of Foreign Languages \\ Voronezh State University of Engineering Technologies \\ Voronezh, Russia \\ e-mail: lena.211080@mail.ru
}

\begin{abstract}
The subject of the study is information ethics as a necessary condition and the driving force of social transformation in the transition to a digital economy. The aim of the work is to find ways to solve this problem by affirming ethical norms and principles in the information space. The article shows the need for theoretical development of ethical foundations in the field of information technology. Some features of human behavior in the information environment with emphasis on the negative consequences of avoiding user responsibility or knowingly criminal activities in the network space have been examined: network piracy, hacking, launching virus programs, involvement in game addiction, collecting all kinds of confidential information without notifying users. The necessity of design work on the implementation of information ethics in a number of areas is shown: theoretical and practical development of ethical principles and standards of behavior in the information space; monitoring compliance with established ethical provisions; reorientation of the labor market to the creation of socially useful information products. There is also the use of the latest psychotechnologies as an example of neuromarketing for effective modeling of human behavior in given conditions; orientation of the education system on the formation of environmental thinking, training and the content of education based on the foundation of information ethics. Besides, there is the need to predict the consequences of robotization, to preserve the enduring value of man and nature; prioritization of living and artificial. The proposed methods for approving the basics of information ethics will prepare the society for the necessary changes and carry out safely and effectively any activity in the information space.
\end{abstract}

Keywords - information ethics, digital economy, information space, information technology.

\section{INTRODUCTION}

The list of leading vectors for the development of the digital economy in Russia until 2024 includes normative regulation, the formation of research competencies and the technical foundation, the information structure and information security, as well as personnel and education. The goals of the training and education area are to create key conditions for training the digital economy, to improve the education system to provide competent personnel of the labor market, taking into account the requirements of the digital economy, to create a motivation system for developing the necessary competencies and for staff participation in the development of the digital economy [14].

An assessment of the innovative development of Russian society based on indicators of the concept and strategy of 2020 [6] and a spatial analysis of the potential of enterprises [2] made it possible to establish themselves in the advisability of changing the ethical plane of public life. The success of information technologies, regardless of their technical excellence, depends on the completeness of meeting the needs of the people for whom they are intended. In this regard, it seems necessary to pay attention to information ethics as an important aspect of human behavior in the context of the digital economy.

The development of information ethics can be viewed from two aspects: broad and narrow.

In a narrow sense, information ethics refers to computer ethics, which is engaged in researching the behavior of people - both professionals and ordinary users - whose work involves the use of computer technology. The formation of computer ethics reflects the fear of the danger of automatic systems getting out of control and, above all, the possibility of technological disasters due to computer errors. On this basis, relevant moral precepts and a kind of etiquette norms are developed.

The most vivid embodiment of computer ethics is in the development of moral codes.

Based on the ethical standards used in the codes, the International Federation for Information Technology (IFIP) recommended the adoption of codes of computer ethics by national organizations in other countries, taking into account local cultural and ethical traditions. The content of individual codes is different from each other, but the basis of individual 
codes is a certain invariant set of moral principles that will not allow the use of a computer to harm other people.

In this regard, computer ethics resembles the so-called laws of robotics formulated by Isaac Asimov in the story "Round dance" (1942).

In a broad sense, the development of information ethics involves the further development of created ethical ideas and principles (utilitarianism, the "golden rule of morality", the categorical imperative of I. Kant, consequentialism, etc.) to the problems of the information society.

Information ethics was formed in response to the requirements of the era of the information society for specialists in various fields and for society as a whole, and at present the importance of its development is constantly growing. Information ethics acts as a link between the manifestation of personal responsibility of citizens and state policy [12]. The sphere of high technologies and computer information almost instantly turned into an actively developing branch of the scientific and technical complex, with a breadth of coverage from transport, medicine, communications, education, banking, industry, electronic commerce to the sphere of services and everyday life. In its totality, it contributes to the replacement of numerous varieties of activities, which were previously characteristic of man, by computer functions. This phenomenon begins to have a strong impact on the spiritual, moral, political, socio-economic life of society, and the mental health of people. Information ethics deals with comprehension of the listed processes. Its formation and development is closely connected with the process of traditional ethics transformation.

\section{RESULTS AND DISCUSSION}

Any cultural and historical integrity that has the form of civilization has its own system of moral values. Total digitalization of the economy creates new problems that require the search for not only a political, economic, but also a moral and ethical solution.

The fact is that the digital economy is not just a set of technologies, but a combination of new social relations that arise when using electronic technologies, electronic infrastructure and services [3].

Ethical problems of the "digital economy" are associated, firstly, with changes in the labor market, the reduction and even disappearance of a number of professions within a short time, and secondly, with the problem of equitable access to the achievements of the "digital revolution", and thirdly, with the emergence of new types of discrimination. These trends are the basis for the risks of increasing social inequality and growing social tension [13].

Global cyberspace, the development of information technology, has generated and continues to generate multiple tasks, the regulation of which requires legal laws, moral regulation, and increasing the effectiveness of administrative measures [10]. It is doubtful that a comprehensive system of sanctions, which includes prohibitions, restrictions and regulations governing these relations and activities, exists. In the information space, it is difficult to trace the actions of each person in fulfilling the specified standards.

In the legal space, there are two fields - moral and legal. Moral laws and norms, in fact, are the laws of human society, which protect the individual and ethnic community in the process of their interconnection and interdependence of development. The coordination of social and personal interests is an unresolved task.

Modern realities are such that the Russian public is not sufficiently prepared to regulate any kind of interaction in the information space, determined by the ethics of moral norms and principles. The global information space creates a sense of impunity for a representative, in particular, a growing generation: virtual reality provides an opportunity for a wide range of independent actions and self-manifestations on a civilized scale. As a result of the absence of externally defined boundaries, deviant behavior in the information space is not uncommon. Examples of deviations are hacking and the development of virus programs. The expansion of the information space, combined with the absence of moral restrictions, will contribute to a large-scale increase in the facts of anonymous theft, credit card thefts and other criminal acts. Economic security is under constant threat of criminal acts in the information environment [9].

The movement of the world to virtual reality increases the risk of deformation of the psyche and poorly controlled consequences of personality changes. It should be noted the negative impact on the personality in the information space through massive immersion in the game form of dependence. The production of computer games, especially online games, is one of the most profitable and active forms of business. The society and the state need to take a set of measures, including moral ones, to protect the population from the harmful effects of gambling, exploiting a person's passion for the game. It is known that the danger of exposure to virtual reality not only creates the illusion of eventful real life and leads away from solving existing problems. Just as with chemical forms of addiction, a negative effect is exerted on the nerve centers, as a result of which gamers experience symptoms similar to manifestations of severe forms of addiction. As a result of abuse, along with emotional oppression, the volitional forms of behavior that are necessary for making decisions and responsibility for the elections are affected, and the passivity of the person increases. It is necessary to take into account the mechanism of mental infection, due to the action of which there is a rapid spread in the society of any dependence. The risk group for gambling addiction includes people with unrealized intellectual potential, with spiritual and moral search queries, who have not found other acceptable ways of expressing themselves. The rapid increase in the number of gamers and immersion in virtual reality threatens the fullfledged formation of personality and the necessary research and professional competencies, motivation for their development, undermining spiritual, moral, socio-economic and mental life. The marginalization of entities that cannot get involved quickly in the rhythm of intensive changes in the economy, in turn, can lead to increased social tension in society. A solution to this problem is impossible without reorienting the labor market from the production of computer 
games to socially useful information products. The ethical aspect is a condition of awareness and a means of control in the course of necessary changes; otherwise all efforts aimed at improving the effectiveness of state socio-economic policy may be in vain if the total number of active population is reduced [16].

The global information space is characterized by the creation of virtually unlimited possibilities for moving various information across information networks, without informing its owner. Due to the extreme ease of moving information flows, the protection of intellectual property in the information space is a difficult problem to solve, both technical and legal, and is accompanied by significant economic costs. As a result, network piracy and hacking are flourishing, network viruses are launched that destroy computer programs and important information, all the information is collected without notifying users.

There is an opinion that the problems of intellectual property in the global network should be initially considered from the standpoint of ethics and only then in the legal and other planes. In this regard, information ethics is not only a sphere of scientific interests, but also an area of current social discussions and moral and legal decisions.

Investing in human capital is a decisive factor in the development of an innovative economy. The creation of a motivation system for the development of the necessary competencies and the active participation of people in the development of the digital economy should be based on the neuromarketing direction. This allows us to monitor the state of human consciousness in the interval from the moment of receipt of information in the form of various stimuli to the appearance of a response to it [8]. It conditionally includes two aspects: the first is the perception of stimuli with a subsequent reaction; the second is the subsequent decisionmaking process. As you know, thought (nervous activity) can occur under the influence of sound, touch, movement, background feelings (moods, emotions), peripheral images, colors. The role of the latter in a person's life can hardly be overestimated: he decisively determines all his actions and reactions, plays a huge role in establishing identity, the process of choice and preference, in the entire complex system of relations of an individual to the world [5]. Neuromarketing as an innovative area characterized by anti-dogmatism, openness and universality, can give a new impetus and give new points of support to specialists interested in developing their field of activity. Neuromarketing technologies are widely used as effective modeling tools in education [1].

Currently, it is customary to distinguish three approaches to modeling human behavior: economic, sociological and psychological [13]. The economic approach is based on the assumption of consumer rationality, guided by the rules of maximizing utility in their actions. Assessment of the usefulness or harmfulness of one's own actions should be adequate and stimulating to positive changes. The labor market should gradually be rebuilt and adapt to new economic realities. The introduction of digital technology can create new quality and new value for the business of almost all industries. The content of constantly growing requirements for the heads of marketing departments in the current conditions of digitalization of the economy is being clarified [4]. The digital transformation of the economy requires significant changes in Russian society, including a change in the management model, the dynamics of the economic system, markets and relations.

The sociological approach is based on the hypothesis that belonging to a particular social environment or the desire to belong to it plays a great role in consumer behavior. In this context, the influence of mainly social and cultural factors on human behavior is considered. Conscious belonging to the information space, together with the necessary moral principles, contributes to a more responsible behavior. Social adaptation to the digital economy is a problem in terms of human-work relationships, as well as in terms of how to obtain information. In addition, the information challenges of the time affect the reproductive system and the environment, and synthetic technologies are actively destroying natural resources and ecosystems. Maintaining high competition in the development of advanced technologies will not give effect without efforts to protect the environment, and in this matter, along with the interaction of states and public organizations for the protection and protection of the environment, the social role of education is still great. Its focus and effectiveness determine the prospects for the development of mankind. Society needs to realize that it belongs not only to the information environment, but also to nature.

The world is changing its attitude towards all types of education, and it is clear that it should not be focused on social, technical or economic progress. The reason for attention to education is the understanding of the most important values of nature and man, as part of it, a departure from anthropocentrism and the desire to pump out Earth's resources and consumer space exploration. Revolutionary shifts in people's minds became noticeable against the backdrop of the negative consequences of land devastation, the soulless extermination of flora and fauna, the growth of urbanization, and climate change. The reality of the threat to all living things poses the problem of reorienting the educational system to the formation of ecological thinking, which includes understanding the causeeffect relationships between human actions or inaction and subsequent changes in the environment, the need to restore the harmony of human existence and nature. To solve the difficult task of survival of flora, fauna, renewal of natural resources, humanity will have to take responsibility for the mistakes made and increase the effectiveness of our own actions. Education as the main means of human development throughout his life is called upon to serve society through the continuous reproduction of spiritual values.

Training and the content of education in the transition to a digital economy should be based on a solid foundation of information ethics and modern psychotechnology.

The psychological approach is based on the assertion of the main role in the behavior of a person of his inner qualities. At the same time, the influence on the behavior of psychological characteristics, such as personality, life experience, and the use of emotion energy for human development is being actively studied [11]. However, it should be borne in mind the ethical aspect of controlling emotions by 
affecting the emotiogenic centers of the brain, which can lead to uncontrolled hormonal processes and subsequent endocrine rearrangements. Insufficient understanding of the consequences of interference in the human psyche at the neural level, the use of the achievements of psychological science for selfish purposes, requires a review of the instrumental role of psychology and the approval of the ethical foundations of the application of knowledge.

Attempts to change the essence of man through genetic engineering and chipization contain the potential for destruction, represent the danger of replacing the properties of the individual and personality, and oppress the human nature. Since any development is a process of irreversible quantitative and qualitative changes, the artificial transformation of a person within the framework of the corresponding information flow greatly increases the risks of adverse consequences of a not always far-sighted impact on society. The rapid acceleration of future changes seems more dangerous than it might seem at first glance. In the meantime, the type of personality and its psychological properties are formed in conditions of innovation in the era of the development of the digital economy and the informatization of education. Decision making does not occur in isolation and strongly depends on the content of the information environment with certain content [7]. The global information space of the Earth creates the conditions for the emergence of a new vision of the world and the feeling of oneself in it.

Society is actively changing under the influence of information technology, therefore, the very introduction of innovations in the social system presents an important ethical problem and requires raising and enriching the moral potential of the nation, which is possible through open perception and understanding of the whole palette of world cultural, historical and educational experience.

Ethical aspects of behavior in the information environment prepare a person for activities containing confidential information, for example, biometric and other personal information.

Social inquiry encourages engineering to move in a certain direction. The creation of artificial intelligence should not ignore the ethical foundation of creativity. A creative act, as you know, is characterized by a mismatch of purpose and end result. Increasing the responsibility of developers is impossible without a solid moral foundation of society as a whole, which, in our opinion, should control the process at the stages of design and development. There are fears that real people will lose their value and interest the world community much less than at the moment, while the value of a digital human double can increase. What other phenomena might an information and technologically advanced society face? Overcoming the biological boundaries of human potential will not only reduce the natural birth rate, but also suppress the very desire to create a family. An example of young Japanese hobby for dolls, their preference for artificial and virtual women over the present, the opportunity to "buy" a family for one day instead of its real creation should alert the public. In addition, the large number of suicides in modern Japan makes us raise the topic of fashion morality to total robotization.
In the process of making important strategic decisions, it is important to take into account the experience of other countries. The influence of the human factor on the formation of the learning platform in the digital economy is scientifically substantiated. So, in the work of Ch. Kreidl, U. Dittler the idea of competitiveness of a higher school graduate from the perspective of a European employer and the realities of educational institutions in Germany, the Netherlands and Switzerland is systematized. It is shown that the use of digital services of students and communication devices in the classroom creates certain obstacles that make it difficult to obtain the necessary competencies. A large amount of information from communication with the "network" is an obstacle to classes in $40 \%$ of responses [15]. This study showed that the competitive aspects in the formation of modern methodological competencies of students is their applied use of digital technologies, taking into account the generational expectations and values of young people, that is, the human factor.

Man and nature as a whole should be of disproportionately greater value than artificial intelligence in any society that wants to survive. Possible errors and miscalculations in the management of human resources, the intellectual potential of society can have a different origin. Investing in human capital is the driving force behind the development of an innovative economy.

Human resources are becoming the most valuable and economically significant resource of society in the context of the development of the digital economy. They are also - the most important source of competitive advantage of enterprises. Therefore, improving the quality of human resources is a decisive factor in the development of the digital economy.

Traditionally, investing in human resources includes investments in obtaining education, in industrial training, in healthcare, in the migration of workers and their families when changing employment conditions, in the search for economically important information. The most important of these is investing in health and education. As a result, the quality of human capital is significantly improved.

The psychological attitudes and mentality of the people in certain cases can complicate the formation and development of the digital economy. Improving the sustainability of human potential in the context of the digitalization of the economy initially involves reducing the risks of increasing social inequality and increasing social tension, and only then improving the training quality of specialists in the field of information and communication technologies.

Dynamic social development in the modern world without fail will entail a deep transformation of all aspects of the economic sphere of society. The rapid spread of information technology and psychotechnology is an integral part of the existence of a highly accurate and efficient economy. The requirements for the individual as a subject of the digital economy are increasing. 


\section{CONCLUSION}

In the period of formation of the digital economy, it is necessary to take into account moral and ethical provisions. Design work on the implementation of information ethics should be carried out in a number of areas:

- theoretical and practical development of ethical principles and norms of behavior in the information space;

- monitoring compliance with established ethical provisions;

- reorientation of the labor market to socially useful information products;

- education orientation towards the formation of environmental thinking, training of personnel and the content of education based on the information ethics foundation;

- wise and responsible usage of the latest psychotechnologies to effectively model human behavior in given conditions;

- prediction of the consequences of robotization to preserve the enduring value of man and nature;

- prioritization of living and artificial.

Thus, to regulate the problems of information security in the context of the digitalization of the economy, it is difficult to overestimate the influence of information ethics on the individual. The digital format of life must certainly be linked to moral values. The development of information ethics is a priority task facing the education and training system. The ethical foundation will allow efficiently and safely carry out any activity in the conditions of information space. Information ethics should become an integral part of the development of the digital economy. The latter cannot be formed without full ethical functioning. The survival of society depends on the chosen priority in the arrangement of the values of the living and the artificial. It is necessary to take into account the human factor in the global development of the world, make necessary adjustments in advance and make investments in strengthening health, in particular mental health, to extend the person's working life, and invest in the education and mobility of workers in the event of structural changes in the labor market. In the conditions of innovative transformations of the economy, it is human capital that acts as its driving force, and information ethics is a factor in the development of the digital economy.

\section{References}

[1] M. Ababkova, Technologies of neuromarketing in education, Moscow: Conflict Development Fund, 2017, 290 p.

[2] Y.P. Anisimov, Y.V. Zhuravlev, I.V. Kuksova, E.I. Balabanova A.Y. Zhilnikov, T.V. Elagina, "Spatial analysis of the development of innovative potential of enterprises", Proc. of Voronezh State Univer. of Engineer. Technol., vol. 81, no. 1, pp. 391-396, 2019, Retrieved from: https://doi.org/10.20914/2310-1202-2019-1-391-396

[3] I.D. Afanasenko, V.V. Borisov, "Digital economy and socio-ethical values", Proc. of St. Petersburg State Univer. of Econ., vol. 5, no. 113, pp. 7-11, 2018.

[4] O.N. Belenov, I.V. Goncharova, "Digital competencies of heads of marketing departments", Proc. of Voronezh State Univer. Ser. Econ. and Manag., no. 3, pp. 93-99, 2019.

[5] V.I. Zhunina, A.E. Zhuravlyova, "Modern neuromarketing: features and prospects of application", Economics. State. Society (Electr. J. of Sci. Publ. Stud. And Young. UIU RANEPA), no. 2, 2018, Retrieved from: http://ego.uapa.ru/ru/issue/2018/02/7/

[6] Y.V. Zhuravlev, I.V. Kuksova, E.A. Gubertov, L.I. Churikov, "Evaluation of innovative development of the Russian Federation based on the 2020 vision and strategy indicators", Proc. of Voronezh State Univer. of Engineer. Technol., vol. 81, no. 2, pp. 377-382, 2019, Retrieved from: https://doi.org/10.20914/2310-1202-2019-2-377-382

[7] D. Kaplunov, Neurocopyrating. 100 techniques of influence with the help of the text, Moscow: Publ. house "E", 2017, 352 p.

[8] E.D. Leskova, E.G. Telicheva, "Ethics of the use of neuromarketing technologies“, Sci. notes of PNU, vol. 10, no. 1, pp. 250-256, 2019.

[9] Y.M. Sokolinskaya, E.A. Kolesnichenko, "Criminalization as a main threat to economic security", Proc. of Voronezh State Univer. of Engineeri. Technol., vol. 81, no. 1, pp. 480-484, 2019, Retrieved from: https://doi.org/10.20914/2310-1202-2019-1-480-484

[10] "Digital Russia: A New Reality", McKinsey \& Company Report, July 2017, Retrieved from: https://www.mckinsey.com/ru/our-insights

[11] O.I. Shmyreva, "In the search for structure-forming emotions", Int Rese. J., vol. 1, no. 67, Part 3, pp. 122-124, 2018, Retrieved from: https://doi.org/10.23670/IRJ.2018.67.068

[12] J. Bohn, et al., "Social, economic, and ethical implications of ambient intelligence and ubiquitous computing", Ambient intelligence, Berlin Springer, Heidelberg, 2005, pp. 5-29.

[13] D.A. Endovitsky, I.B. Durakova, Statistical analysis as the Basis for the Practice of Modernizing Personnel Management: International Experience, Int. J. of Engineer. and Technol. (UAE), vol. 7, no. 4(38), pp. 145-151, 2018, Retrieved from: https://doi.org /10.14419/ijet.v7i4.38.24341

[14] A.V. Guryanova et al., Socio-ethical problems of the digital economy: challenges and risks, Digital Transformation of the Economy: Challenges, Trends and New Opportunities. Cham: Springer, 2020, pp. 96-102.

[15] Ch. Kreidl, D. Ullrich, Wo stehen wir? Ergebnisse einer umfassenden empirischen Studie zu Lernen und Unterricht an Hochschulen heute, Hochschule der Zukunft, Wiesbaden: Springer VS, 2018, pp. 35-62.

[16] Fiona Sussan, J.Acs. Zoltan, "The digital entrepreneurial ecosystem", Small Busin. Econ., vol. 49, no. 1, pp. 55-73, 2017. 